\title{
Food Oral Processing in Humans: Links Between Physiological Parameters, Release of Flavour Stimuli and Flavour Perception of Food
}

\author{
Gilles Feron $^{\mathrm{a}^{*}}$ And Christian SAlles ${ }^{\mathrm{a}}$ \\ ${ }^{a}$ Centre des Sciences du Goût et de l'Alimentation, AgroSup Dijon, CNRS, INRA, Univ. Bourgogne \\ Franche-Comté, F-21000 Dijon, France \\ ${ }^{*}$ Corresponding author \\ gilles.feron@dijon.inra.fr \\ TEL: +33-3-806932 78 \\ Received: 27 September 2016; Published online: 18 April 2018 \\ Invited paper from the IFA-event "Food Rheology and Texture" e-conference for undergraduate 6 MASTER \\ students
}

\begin{abstract}
In humans, food oral processing (FOP) is the first step in the digestive process. It prepares the food for swallowing and to undergo the process of digestion. During chewing, the food is comminuted by the combined action of chewing and saliva to form a bolus. The particle size of the bolus is reduced due to the action of the tongue and the teeth, and the saliva is continuously produced by the salivary glands to humidify and impregnate the food. Saliva lubricates the bolus and enables the cohesion of particles to prepare for swallowing. During food oral processing, the compounds responsible for food flavour and taste are released, leading to the perception of food organoleptic properties and significantly contributing to the consumer's acceptability of the product. Understanding this process of food breakdown and bolus formation thus appears to be a way to revisit food functional properties. However, this process is extremely complex, and as such, its description necessitates a combination of many quantities from different disciplines, i.e., physics, chemistry, physiology, psychology, behavioural science and food science. It depends, on one hand, on food properties and on the other hand, it depends on oral physiology. However, large inter-individual variability is commonly observed, which has important consequences on flavour release and perception. The challenge for the food industry is to be able to develop food considering this large variability, and sensory and nutritional constraints. This challenge is particularly relevant when specific populations (i.e., elderly, infants or obese subjects) are considered.
\end{abstract}

Keywords: Mastication; Saliva; Food Bolus; Aroma; Taste

\section{Food breakdown and bolus formation in the mouth}

\subsection{Role of mastication}

In humans, the mastication process involves the coordinated activity of masticatory muscles (masseter temporalis, lateral and medial ptery- goids), jaw, lips, tongue and saliva. Food breakdown begins by the rhythmic movements of opening and closing the mandible while the jaws and tongue reposition the food between the teeth. The tongue gathers the particles to form a bolus, and then transports the bolus to the posterior part of the oral cavity to initiate swallowing. Salivation, which is mechanically stimulated 
by chewing and is physico-chemically stimulated by the food components, enables lubrication of the bolus, aggregation of particles and swallowing (Salles et al., 2011).

Masticatory ability is closely related to the number of teeth, and a decrease in the ability to chew occurs when less than 20 teeth are present. Functional chewing difficulties particularly occur in the elderly, with a decline in general health that leads to tooth loss and hyposalivation, but ageing has little effect on chewing in older people with proper oral health status. In the case of infants, physiological changes allow them to move progressively from sucking to chewing and thus from liquid to solid foods. Infant masticatory efficiency is stimulated by exposure to more or less complex food textures (Nicklaus, Demonteil, \& Tournier, 2015).

Chewing is mainly influenced by the composition of the food, its texture (Kohyama \& Mioche, 2004) and the chewing parameters (Yven, Culioli, \& Mioche, 2005). Indeed, the food's texture has a large influence on the chewing process. In particular, the number of chewing cycles preceding the first swallowing depends on the texture of the food. A dry, hard food requires many chewing cycles to be fragmented into particles and impregnated by saliva before being swallowed (Prinz \& Lucas, 1995). In fact, to be swallowed, the food bolus must reach adequate levels of comminution (particle size) and of lubrication or moistening (Hutchings \& Lillford, 1988). For hard, brittle foods, such as peanuts, almonds, carrots, it appears that the particle sizes are similar among individuals, but the duration of chewing sequences and the number of cycles vary (Mishellany, Woda, Labas, \& Peyron, 2006). In most studies, the breakdown rate is determined by successive sieving bowls of particles (van der Bilt \& Fontijn-Tekamp, 2004). However, for non-brittle foods, other bolus properties triggering swallowing have been evidenced. In particular, food bolus consistency has been highlighted as an important property to trigger swallowing during cheese consumption (Yven et al., 2012). In this case, it is likely that the continuous phase of the food bolus, resulting from a mix between saliva and food, is as important as particle size.

\subsection{Role of salivation}

Saliva is a biological fluid that bathes and moisturizes the oropharyngeal cavity. It is produced by three pairs of major (parotid, sublingual and submandibular) and minor (buccal, labial, lingual, and palate) glands. A distinction is made between saliva at rest, which corresponds to the liquid produced without any stimulation (mechanical, chemical or trigeminal), and stimulated saliva that results from a stimulation, more often during the consumption of liquid or solid food (Schipper, Silletti, \& Vingerhoeds, 2007).

During the chewing process, stimulated saliva contributes to the formation of a food bolus that can be swallowed (Yven, Guessasma, Chaunier, Della Valle, \& Salles, 2010) and to the release of active substances. Due to its moisturizing, lubrication and hydrolytic capacities, saliva changes the structure and mechanical and physical properties of the food bolus and thus the sensory perception of texture and flavour (Yven et al., 2005). Moreover, large inter-individual variability was observed (Quintana et al., 2009; Feron et al., 2014). Indeed, studies conducted on the incorporation of saliva during chewing showed a level of moistening of up to $80 \%$, depending on the matrices and subjects considered (Guichard et al., 2008; Guinard, ZoumasMorse, Walchak, \& Simpson, 1997).

\subsection{Particle size reduction and swallowing event}

At the end of the chewing sequence, a double threshold - comminution and lubrication - needed to trigger aspiration was proposed (Hutchings \& Lillford, 1988). These two parameters can be connected to one dimension, represented by the cohesion of the food bolus (Prinz \& Lucas, 1995). During chewing and thus the production of smaller and smaller particles, saliva gradually reduces the space between particles and thus increases the cohesive forces between them. For instance, an analysis of fragments of different kinds of cereal flakes (breakfast type) showed the importance of the breaking behaviour of the product on human mastication. The fragmentation phase is quickly followed, in less than ten cy- 
cles of mastication, by a particle agglomeration phase. The two phenomena are related to the amplitude of the masticatory force and its change during the chewing process (Yven et al., 2010). The gradual disintegration of the food matrix in the mouth during chewing leads to variations in texture perception, which although they are specific to each type of food, they can change over time, reflecting particle size reduction and the increased cohesion of lubricated particles (Lenfant, Loret, Pineau, Hartmann, \& Martin, 2009). The harder food is to swallow, the longer the time that is needed for Food Oral Processing (FOP) (Chen \& Lolivret, 2011).

In conclusion, this part of in-mouth food breakdown and bolus formation can be likened to a food process that leads a product far from what is originally placed in the mouth. It will thus impact the dynamics of the release of active substances and their functionalities (organoleptic, nutritional, etc.) (Salles et al., 2011).

\section{FOP, flavour release and perception}

\subsection{Aroma}

In the mouth, aroma release and perception are strongly linked to oral parameters (chewing, salivation, breathing, swallowing) (Rolls \& Rolls, 1997). Furthermore, individual differences in the profiles of chewing and swallowing explain interindividual differences in the retronasal release of aroma compounds (Ruijschop, Burgering, Jacobs, \& Boelrijk, 2009).

In vivo, aromatic perception depends on the concentration of flavour in the nasopharynx, which itself is affected by the rate of release of the food aroma compounds in the oral cavity (van Ruth \& Roozen, 2000). The release of aroma compounds in the mouth is affected by the composition of the food matrix and the entire oral process (Figure 1). All phenomena that occur between food intake and swallowing increase the surface area available for exchange, dilution and partial dissolution in saliva, which may affect the release of aroma compounds (Bakker et al., 1996).

For instance, in cheese and for one subject, the time corresponding to the maximum re- lease of aroma compounds, such as hexane-2one, hexane-2-ol and ethylhexanoate, are very close, but large inter-individual differences regarding volatile release kinetic parameters have been reported (Pionnier et al., 2004). These differences are attributed to different oral physiology characteristics and oral processing behaviours. In a study conducted on 43 subjects consuming cheese products, a maximum concentration and total amount of aroma released in the mouth have been linked to the number of chewing bursts, high masticatory activity, low salivary flow and a low level of salivary $\alpha$-amylase (due to a retention effect by this protein in this case) (Feron et al., 2014). These relationships are explained by a higher breakdown of the food, followed by a higher spreadability of the food bolus and a higher coating at the surface of the oral cavity. The consequence is a higher transfer of volatile compounds from the oral cavity to the nasal cavity through the retronasal way. Similar observations were reported for candies (Blissett, Hort, \& Taylor, 2006). On perception, the release rate of aroma compounds, rather than the maximum concentration released in the mouth, has shown an important determinant for the perception of aroma (Mestres, Moran, Jordan, \& Buettner, 2005; Boland, Delahunty, \& van Ruth, 2006). However, aroma perception was explained by masticatory behaviour and saliva properties and was less extensively related to aroma release profiles (Feron \& Guichard, 2014).

Inter-individual differences in swallowing have also been reported (Guichard et al., 2008). These differences have a significant effect on the release profile of flavour compounds measured in nasal emanations (Buettner, 2002b). Thus, some subjects will continuously release aroma compounds as they chew food, other subjects will release these compounds during chewing, with interruptions during swallowing, while some will release these compounds only after swallowing. This phenomenon is explained by differences in soft palate positioning, which allows opening and closing the mouth and the retronasal control of gas transfer (Mishellany-Dutour et al., 2012). When moistening the bolus, various factors related to the composition of saliva will directly impact both the quality and quantity of aroma release. One can cite the work of Guinard and 
co-workers (Guinard, ZoumasMorse, \& Walchak, 1997), Van Ruth and co-workers (van Ruth \& Roozen, 2000), Buettner (Buettner, 2002a; Buettner, Beer, Hannig, Settles, \& Schieberle, 2002) and Pagès and co-workers (Pagès-Hélary, Andriot, Guichard, \& Canon, 2014) as examples, as these authors have described the role of salivary flow and composition on in-mouth retention and the degradation of certain volatile compounds. Some of the salivary compounds that seem to be the most involved are mucins, certain enzymes and small molecules, especially salts, and the $\mathrm{pH}$. For instance, the retention of aroma molecules (ketones and esters) by mucin increases as a function of the aliphatic chain length, suggesting the involvement of hydrophobic effects for these molecules (Pagès-Hélary et al., 2014). Salivary esterases and dehydrogenases can lead to the release of alcohols from esters and to the oxidation of alcohols to aldehydes, respectively (Ployon, Morzel, \& Canon, 2017). Ultimately, a high salivary amount of salts increases aroma release in the oral cavity due to the "salting-out" effect, which principally depends on the hydrophobic properties of the volatile molecule (Salles et al., 2011).

Furthermore, the action of salivary $\alpha$-amylase may induce a change in the viscosity of a solution containing starch, thus having an impact on the release of aroma compounds (Ferry, Hort, Mitchell, Lagarrigue, \& Pamies, 2004). Authors have shown that action of the enzyme on two solutions of the same viscosity but different levels of starch resulted in a greater decrease in the viscosity of the solution richer in starch, which explains its more intense release of aroma compounds. In both cases, increasing the amount of $\alpha$-amylase leads to a more rapid decrease of viscosity. The effect of saliva on the release of aroma compounds from bread was also shown in in vitro systems mimicking chewing conditions (Poette et al., 2010).

Finally, chewing behaviour and aroma release varies depending on food properties. For instance, interactions between the composition of cheese matrices and chewing behaviour of individuals affects the release of aroma compounds in the mouth (Figure 2). In particular, a reduction in fat content increases the release of aroma compounds (Feron et al., 2014). This is due to a greater masticatory work due to the increased hardness of the matrices with less fat content, which thus leads to a higher release rate from the matrix. Moreover, the use of fat to decrease the matrix melting point and a lower mixing speed of ingredients during cheese preparation leads to a less hard cheese. In this case, the expected increase in the release of aroma compounds due to the greater mobility of the compounds was partially compensated by lower chewing activity. Indeed, velum opening depends on chewing behaviour (frequency and amplitude). Thus, in this case, the transfer of aroma compounds from the oral cavity to the nasal cavity due to the velum opening was higher for the hardest cheeses.

\subsection{Taste}

As for the volatile compounds, the release of taste compounds in the mouth during consumption of a food depends on its composition and texture and on the oral physiology parameters of individuals (Figure 1).

The temporal release profile of tasting compounds is highly dependent on the nature of the food matrix. For instance, the citric acid of an orange will be released much more quickly in the mouth than in a gelatin gel, but it will also decrease more rapidly after reaching its maximum (Davidson, Linforth, Hollowood, \& Taylor, 2000, 1998).

Similar observations have been reported for cheeses of different textures. Although soft cheese contains more salt than hard cheese, there is a much greater maximum saltiness intensity for salted hard cheese (Davidson et al., 2000, 1998). This significant difference is due to the matrix properties and chemical composition of cheeses (Figure 2). Soft cheese requires low chewing effort and thus breaks easily in the mouth, unlike the hard cheese, in which chewing requires more mechanical energy, and therefore the cheese undergoes a partial breakdown before swallowing. This means that some of the salts are not released into the oral cavity for soft cheese, thus explaining the much lower intensity than that observed for hard cheese. The distribution of the stimulus into the food matrix also plays a role in the release kinetics. When the salt is localized 
Food oral processing in humans $\mid 5$

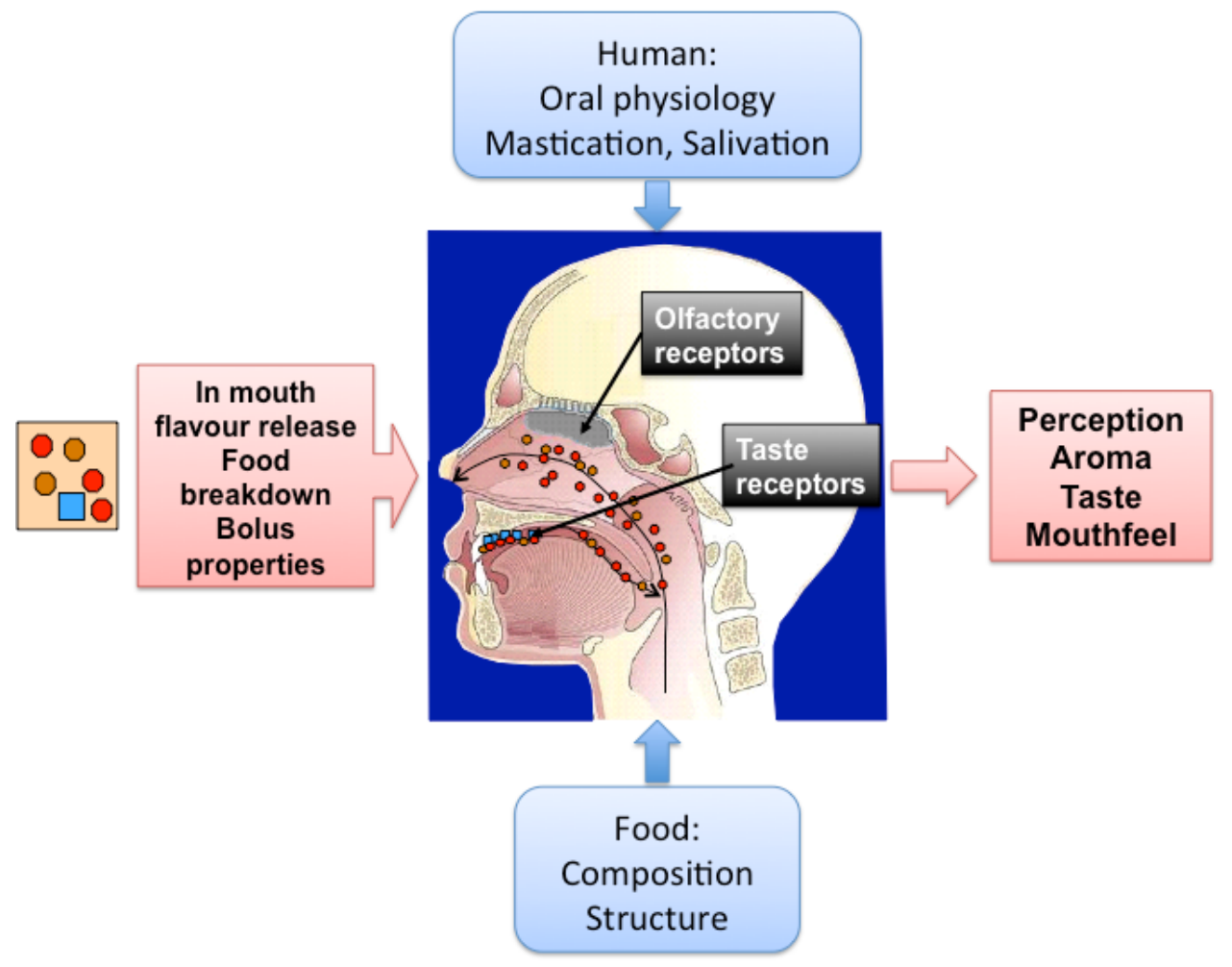

Figure 1: Schematic representation of oral food breakdown, leading to the release and perception of taste and aroma. During food oral processing (FOP), the food product is broken down in the mouth to form a food bolus. The properties of the food bolus and its dynamics of evolution in the mouth depends on the subject's physiology and on the food's properties. During FOP, aroma and taste compounds are released in the oral and nasal cavity, where they reach the receptors and are perceived. All these events contribute to acceptance or rejection of the food product by the consumer (adapted from Feron, Salles, and Guichard (2013).

only on the surface of the food, it is detected more quickly than if it is included in the matrix. Furthermore, the nature of the matrix is also important. For dry products, for example, a phase of hydration of the matrix by saliva is observed, in which saliva plays a solvent role and allows the compounds to come into contact with the receptors.

For the same food matrix in one individual, the release kinetics of a tasting compound are similar and differ only by the concentration of the compound in the matrix (Pionnier et al., 2004). Moreover, food matrix composition also plays a role in the release of tasting compounds in the mouth, either directly through interac- tions with the compounds of the matrix or indirectly by changes in the textural properties of the products, which induce a change in physiological behaviours during mastication of the product (Phan et al., 2008). In contrast, inter-individual differences are very important and essentially depend on the physiological characteristics of subjects. These characteristics are critical to the release kinetics of the stimuli. In the case of mastication of solid food, the release of sodium in the mouth is positively correlated to the total chewing duration, but it is negatively correlated with salivary flow, chewing frequency, rate of swallowing and masticatory efficiency. Flow and masticatory efficiency play a role in the speed of per- 
$6 \mid$ Feron and Salles

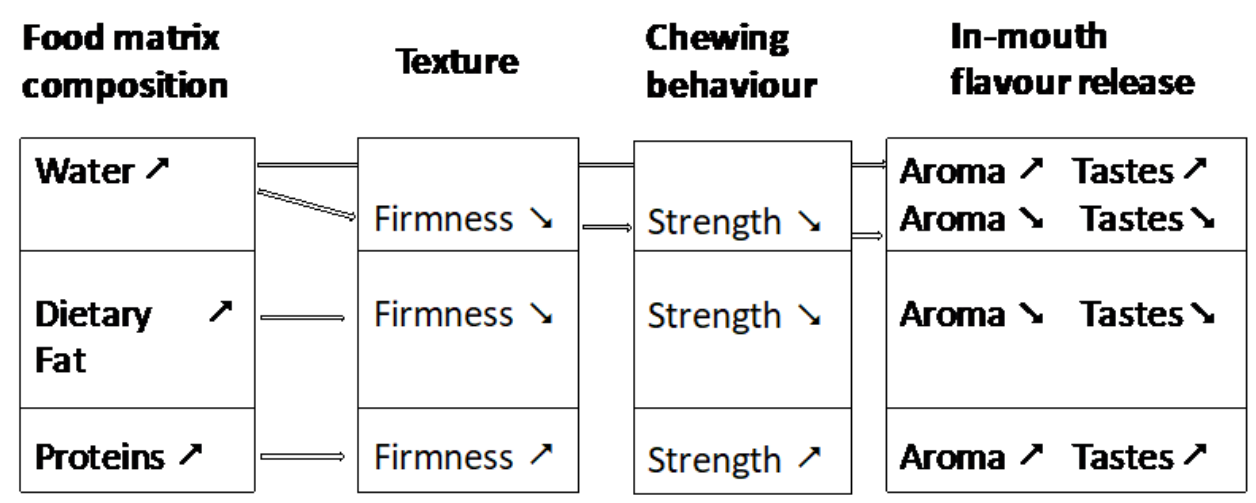

Figure 2: Influence of cheese matrix composition on texture, chewing behaviour and in-mouth release of flavour compounds (adapted from Feron, Salles, and Guichard (2013). Increasing the matrix water amount leads to two contradictory effects: (i) higher aroma and taste release, and (ii) decreased firmness, lower chewing activity and thus lower aroma and taste release. This second effect is also observed when the matrix fat content is increased. In contrast, increasing the matrix protein amount leads to higher firmness, higher chewing activity and thus higher aroma and taste release during consumption.

ception and not the intensity of saltiness (Phan et al., 2008).

If one focuses more on saliva and its composition, saliva may, due to its moisturizing properties and hydrolytic capacities, promote disintegration of the matrix and thus the release of palatable active substances. This is the case with the salivary $\alpha$-amylase that hydrolyses the starch contained in food to release maltose, which has a sweetening power of 0.33 (compared to sucrose). This effect has also been particularly illustrated by the work of Ferry and co-workers, (Ferry et al., 2006) which showed a direct relationship between the level of $\alpha$-amylase activity in saliva and the saltiness of starchy matrices. In this case, amylase has the effect of enhancing the disintegration of the product, which releases sodium in the saliva medium, and therefore enhances its perception. Furthermore, saliva itself contains tasting compounds at a more or less high concentration. This is the case for certain amino acids and certain peptides with specific organoleptic properties (bitter, sweet and umami), certain salts (sodium, potassium and calcium), sugars (glucose, fructose) and fatty acids. These compounds constantly stimulate the taste receptors on the tongue. Interestingly, the salivary concentrations of some of these compounds largely cover the de- tection limits observed in humans. This is the case of sodium, calcium, and certain amino acids (histidine and glutamate). It is therefore likely that the sensory perception of these tasting substances, when they are added in the food, are dependent on their salivary concentrations, which are subject to high inter-individual variability. For instance, salivary calcium and sodium levels differed, respectively, from 22.6 to $1800 \mu \mathrm{g} / \mathrm{ml}$ and 140 to $275 \mu \mathrm{g} / \mathrm{ml}$ in saliva, depending on the subject. These differences may explain variability in the perception and thus the acceptability of some food products. For instance, it has been shown that an individual with a high salivary sodium concentration is less sensitive to saltiness (Bartoshuk, 1978). It is likely that this individual will tend to favour higher sodium levels in food that an individual with a very low salivary sodium concentration. This is of course a hypothesis that should be tested on a large number of salivary compounds, particularly those related to sweetness and fattiness.

\subsection{Other food components}

Beyond taste and aroma, other compounds may directly impact the perception of the food without having an "a priori" flavour. This the case 
of $\mathrm{CO}_{2}$ perception in carbonated beverages. It was long considered that the $\mathrm{CO}_{2}$ perception was mainly due to physical phenomena linked to bubbles bursting in the mouth. However, studies have shown that this feeling was under the control of an enzyme found in saliva, carbonic anhydrase VI (CAH VI) or gustin. This enzyme catalyses the conversion of $\mathrm{CO}_{2}$ into carbonic acid. With a turnover of $10^{-5}$ Mole per second, this enzyme has one of the highest velocities ever known, which makes it compatible with food in the mouth for a very short time. This role in $\mathrm{CO}_{2}$ trigeminal perception has been demonstrated by Dessirier and co-workers (Dessirier, Simons, Carstens, O'Mahony, \& Carstens, 2000) during psychophysical studies in humans using an inhibitor of the enzyme.

Mouth perception of phenolic compounds, such as tannins, is another known example of the possible role of saliva in perception through the sensation of astringency provided by these compounds. Astringency is often described as a drying sensation in the mouth. It is generally accepted that this sensation results from the interaction of certain proline-rich salivary proteins (PRP) and phenolic compounds in food (de Wijk \& Prinz, 2005; Prinz \& Lucas, 2000). These interactions result in a decrease in the lubricating properties of saliva, leading to this drying sensation.

\section{Prospect}

\subsection{Linking dynamic of food bolus formation and sensory perception}

To date, most of the published works that have attempted to relay food bolus properties, aroma and taste release and food sensory perception have been focused on the bolus just before swallowing. However, in-mouth food breakdown is a dynamic process. Therefore, it is of a high interest to evaluate how the food bolus changes during FOP in a dynamic way and the consequences on aroma and taste release and then perception. Some methodologies exist to continuously measure aroma release and flavour perception during food consumption. Sensors can be used to directly monitor taste release in the mouth (Emorine et al., 2012). Aroma release can also be measured continuously with spectroscopic measurements, such as APCI (Atmospheric Pressure Chemical Ionization) (Le Quéré, Gierczynski, Langlois, \& Sémon, 2006) or PTRMS (Proton Transfer Reaction - Mass Spectrometry) (Le Quéré \& Guichard, 2011). For sensory analysis, TI (Time Intensity) or TDS (Temporal Dominance Sensations) are relevant methodologies (Labbe, Schlich, Pineau, Gilbert, \& Martin, 2009). The most challenging aspect concerns the food bolus. As far as we know, it is not possible to follow food bolus property changes in situ. Moreover, evaluating food bolus rheological characteristics requires methodological developments with particular constraints (small samples, large heterogeneity, large between subject variability, etc.). These constraints lead to the fact that (i) the bolus must be collected at different times during the chewing sequence, (ii) we cannot use a single method for characterization of the bolus collected at different stages, and (iii) we need to find a methodology that can cover the large variability observed within the population. However, some very recent works showed clear relationships between bolus property changes, chewing behaviours and sensory perception during the consumption of sausages (de Lavergne, Derks, Ketel, de Wijk, \& Stieger, 2015). This interesting study highlights an interest to conduct research in the field.

\subsection{Specific populations}

Most of the studies described in the previous chapters have been principally conducted on young, healthy populations (typically from 18 years old to 60 years old). However, it is a big challenge to characterize more specific populations, such as elderly people, infants or obese individuals.

To date, these populations have been poorly investigated, as they represent strong demographic challenges. However, some oral characteristics have been described in the literature for these populations.

For instance, elderly saliva is characterized by low flow and a high level of proteins, $\alpha$-amylase

IJFS | April 2018 | Volume 7 | pages 1-12 
and ions (Vandenberghe-Descamps et al., 2016; Nagler \& Hershkovich, 2005; Hershkovich \& Nagler, 2004). In terms of dentition, elderly show a low amount of functional units compared to a younger population (Vandenberghe-Descamps et al., 2016). These differences significantly impact the capacity to chew and form a swallowable food bolus (Mioche, Bourdiol, Monier, Martin, \& Cormier, 2004). In infants, the first year of infancy corresponds to food oral exposure and experiences. In parallel, infants develop masticatory and digestion capacities with the development of teeth and changes in saliva properties (Nicklaus et al., 2015; Morzel et al., 2012). However, in this population, a food bolus is difficult to collect, though some recent investigation methodologies have been proposed (Tournier, Rodrigues, Canon, Salles, \& Feron, 2015). Thus, its rheological properties are difficult to evaluate.

Regarding in-mouth aroma and taste release and their link with FOP, the literature is quite scarce for infants and the elderly. However, it is likely that the phenomena in these populations will be different compared to other individuals. One of the difficulties is to develop investigation methodologies that are specific to these particular populations, especially infants. This issue represents a real challenge for the scientific community working in the field.

Another population that should be of high interest to investigate is overweight and obese individuals. This population represents a true demographic challenge in terms of health issues. Surprisingly, this population has been poorly investigated in relation to FOP, while some scientific results led to the hypothesis that this population has a particular FOP profile. For instance, it has been shown that obese subjects have lower salivary flow and altered oral health (Modeer, Blomberg, Wondimu, Julihn, \& Marcus, 2010), particular salivary compositions (Vors et al., 2015) and different chewing behaviours in comparison to a normal weight population (Godlewski et al., 2011). Moreover, in vitro experiments conducted on obese subjects' saliva showed a lower aroma release pattern compared to saliva from normal-weight subjects ( $\mathrm{Pi}$ ombino et al., 2014). Therefore, it is likely that the in vivo processes of aroma and taste release in the mouth and the nasal cavity are different in this population.

\section{Conclusion}

This review aimed to show the important role of chewing and salivation in in-mouth food breakdown and the release of flavour from the food bolus, with particular attention to organoleptic components. This review also tried to provide an interesting perspective on the role and contribution of FOP in specific populations.

An important point in all studies on chewing and salivation that have been conducted on a significant number of human subjects is the extreme difference between inter-subject variability and intra-subject variability. The links between this large physiological variability and that of the different sensory phenotypes observed in the human population are yet to be established. Moreover, this point clearly raises the question of considering this variability in reverse engineering approaches aimed at rationally designing food for the delivery of particular functionalities along the gut. Only integrated and systemic scientific approaches involving many different disciplines, starting from the physico-chemistry of food to physiology and genetics, will help prioritize different oral events and their effects and will then establish the best strategies for improving the food supply.

\section{References}

Bakker, J., Brown, W. E., Hills, B. M., Boudaud, N., Wilson, C. E., \& Harrison, M. (1996). Flavour science recent developments. In A. Taylor \& D. Mottram (Eds.), (Chap. Effect of the food matrix on flavour release and perception, Vol. 197, pp. 369-374). Cambridge: The Royal Society of Chemistry.

Bartoshuk, L. M. (1978). The psychophysics of taste. The American Journal of Clinical Nutrition, 31(6), 1068-1077.

Blissett, A., Hort, J., \& Taylor, A. J. (2006). Influence of chewing and swallowing behavior on volatile release in two confectionery systems. Journal of Texture Studies, 37(5), 
Food oral processing in humans $\mid 9$

476-496. doi:10.1111/j.1745-4603.2006. 00064.x

Boland, A. B., Delahunty, C. M., \& van Ruth, S. M. (2006). Influence of the texture of gelatin gels and pectin gels on strawberry flavour release and perception. Food Chemistry, 96(3), 452-460. doi:10 . $1016 / \mathrm{j}$. foodchem.2005.02.027

Buettner, A. (2002a). Influence of human saliva on odorant concentrations. 2. aldehydes, alcohols, 3-alkyl-2-methoxypyrazines, methoxyphenols, and 3-hydroxy-4,5dimethyl-2(5h)-furanone. Journal of Agricultural and Food Chemistry, 50(24), 7105-7110. doi:10.1021/jf020714o

Buettner, A. (2002b). Influence of human salivary enzymes on odorant concentration changes occurring in vivo. 1. esters and thiols. Journal of Agricultural and Food Chemistry, 50(11), 3283-3289. doi:10 . 1021/jf011586r

Buettner, A., Beer, A., Hannig, C., Settles, M., \& Schieberle, P. (2002). Physiological and analytical studies on flavor perception dynamics as induced by the eating and swallowing process. Food Quality and Preference, 13(7-8), 497-504. 4th Pangborn Sensory Science Symposium 2001: A Sense Odyssey, DIJON, FRANCE, JUL 22-26, 2001. doi:10.1016/S0950-3293(02)00052-6

Chen, J. \& Lolivret, L. (2011). The determining role of bolus rheology in triggering a swallowing. Food Hydrocolloids, 25 (3), 325-332. doi:10.1016/j.foodhyd.2010.06.010

Davidson, J. M., Linforth, R. S. T., \& Taylor, A. J. (1998). In-mouth measurement of ph and conductivity during eating. Journal of Agricultural and Food Chemistry, 46(12), 5210-5214. doi:10.1021/jf9806558

Davidson, J. M., Linforth, R. S. T., Hollowood, T. A., \& Taylor, A. J. (2000). Release of non-volatile flavor compounds in vivo. In Flavor release (Chap. 9, pp. 99-111). doi:10.1021/bk-2000-0763 . ch009. eprint: http://pubs.acs.org/doi/pdf/10.1021/bk2000-0763.ch009

de Lavergne, M. D., Derks, J. A. M., Ketel, E. C., de Wijk, R. A., \& Stieger, M. (2015). Eating behaviour explains differences between individuals in dynamic texture perception of sausages. Food Quality and Preference, 41, 189-200. doi:10.1016/j.foodqual.2014. 12.006

de Wijk, R. A. \& Prinz, J. F. (2005). The role of friction in perceived oral texture. Food Quality and Preference, 16(2), 121-129. doi:10.1016/j.foodqual.2004.03.002

Dessirier, J. M., Simons, C. T., Carstens, M. I., O'Mahony, M., \& Carstens, E. (2000). Psychophysical and neurobiological evidence that the oral sensation elicited by carbonated water is of chemogenic origin. Chemical Senses, 25(3), 277-284. doi:10.1093/ chemse/25.3.277

Emorine, M., Mielle, P., Maratray, J., Septier, C., Thomas-Danguin, T., \& Salles, C. (2012). Use of sensors to measure in-mouth salt release during food chewing. IEEE Sensors Journal, 12(11, SI), 3124-3130. doi:10. 1109/JSEN.2012.2215471

Feron, G. \& Guichard, E. (2014). Mécanismes en bouche et variabilité inter individuelle: liens entre paramétres physiologiques, libération des stimuli sensoriels et perception de l'aliment. Innovations Agronomiques, 36, 15-26.

Feron, G. G., Salles, C. C., \& Guichard, E. E. (2013). Food oral processing understanding, a way to revisit the sensory properties of food. In 6 international conference on proton transfer reaction mass spectrometry and its applications (pp. 46-50). Obergurgl, Austria: Innsbruck University Press. Retrieved from https://hal.archivesouvertes.fr/hal-01001054

Feron, G., Ayed, C., Qannari, E. M., Courcoux, P., Laboure, H., \& Guichard, E. (2014). Understanding aroma release from model cheeses by a statistical multiblock approach on oral processing. Plos One, 9(4). doi:10. 1371/journal.pone

Ferry, A. L., Hort, J., Mitchell, J. R., Lagarrigue, S., \& Pamies, B. (2004). Effect of amylase activity on starch paste viscosity and its implications for flavor perception. Journal of Texture Studies, 35(5), 511-524.

Ferry, A.-L. S., Mitchell, J. R., Hort, J., Hill, S. E., Taylor, A. J., Lagarrigue, S., \& Valles-Pamies, B. (2006). In-mouth amylase activity can reduce perception of salti- 
ness in starch-thickened foods. Journal of Agricultural and Food Chemistry, 54(23), 8869-8873. doi:10.1021/jf061607n

Godlewski, A. E., Veyrune, J. L., Nicolas, E., Ciangura, C. A., Chaussain, C. C., Czernichow, S., ... Hennequin, M. (2011). Effect of dental status on changes in mastication in patients with obesity following bariatric surgery. Plos One, 6(7). doi:10. 1371/journal.pone.0022324

Guichard, E., Sémon, E., Gierczynski, I., Tournier, C., Saint-Eve, A., Souchon, I., ... Labouré, H. (2008). Texture-aroma interactions in dairy products: do in-vivo and in-vitro aroma release explain sensory perception? In 12th weurman symposium (Vol. Chapitre 3. In-vivo measurements in flavour release, pp. 117-120). Interlaken, Switzerland: ZHAW Zürcher Hochschule für Angewandte Wissenschaften. Retrieved from https://hal-univ-bourgogne.archivesouvertes.fr/hal-00712538

Guinard, J. X., ZoumasMorse, C., \& Walchak, C. (1997). Relation between parotid saliva flow and composition and the perception of gustatory and trigeminal stimuli in foods. Physiology \& Behavior, 63(1), 109-118. doi:10.1016/S0031-9384(97)00399-5

Guinard, J. X., ZoumasMorse, C., Walchak, C., \& Simpson, H. (1997). Relation between saliva flow and flavor release from chewing gum. Physiology \& Behavior, 61(4), 591596. doi:10.1016/S0031-9384(96)00508-2

Hershkovich, O. \& Nagler, R. M. (2004). Biochemical analysis of saliva and taste acuity evaluation in patients with burning mouth syndrome, xerostomia and/or gustatory disturbances. Archives of Oral Biology, 49(7), 515-522. doi:10 . 1016/ j . archoralbio.2004.01.012

Hutchings, J. B. \& Lillford, P. J. (1988). The perception of food texture - the philosophy of the breakdown path. Journal of Texture Studies, 19(2), 103-115. doi:10.1111/ j.1745-4603.1988.tb00928.x

Kohyama, K. \& Mioche, L. (2004). Chewing behavior observed at different stages of mastication for six foods, studied by electromyography and jaw kinematics in young and elderly subjects. Journal of Texture Stud- ies, 35(4), 395-414. doi:10.1111/j.17454603.2004.tb00603.x

Labbe, D., Schlich, P., Pineau, N., Gilbert, F., \& Martin, N. (2009). Temporal dominance of sensations and sensory profiling: a comparative study. Food Quality and Preference, 20(3), 216-221. doi:10.1016/j . foodqual. 2008.10.001

Le Quéré, J.-L., Gierczynski, I., Langlois, D., \& Sémon, E. (2006). Nosespace with an ion trap mass spectrometer-quantitative aspects. Developments in Food Science, 43, 589-592.

Le Quéré, J.-L. \& Guichard, E. (2011). Food flavour analyses: traditional and new challenging methods. In 5. international conference on proton transfer reaction mass spectrometry and its applications. Innsbruck university press.

Lenfant, F., Loret, C., Pineau, N., Hartmann, C., \& Martin, N. (2009). Perception of oral food breakdown. the concept of sensory trajectory. Appetite, 52(3), 659-667. doi:10.1016/j.appet.2009.03.003

Mestres, M., Moran, N., Jordan, A., \& Buettner, A. (2005). Aroma release and retronasal perception during and after consumption of flavored whey protein gels with different textures. 1. in vivo release analysis. Journal of Agricultural and Food Chemistry, 53(2), 403-409. doi:10.1021/jf048596n

Mioche, L., Bourdiol, P., Monier, S., Martin, J. F., \& Cormier, D. (2004). Changes in jaw muscles activity with age: effects on food bolus properties. Physiology \& Behavior, 82(4), 621-627. doi:10.1016/j.physbeh. 2004.05 .012

Mishellany, A., Woda, A., Labas, R., \& Peyron, M.-A. (2006). The challenge of mastication: preparing a bolus suitable for deglutition. Dysphagia, 21 (2), 87-94. doi:10.1007/ s00455-006-9014-y

Mishellany-Dutour, A., Woda, A., Laboure, H., Bourdiol, P., Lachaze, P., Guichard, E., \& Feron, G. (2012). Retro-nasal aroma release is correlated with variations in the inmouth air cavity volume after empty deglutition. Plos One, 7(7). doi:10.1371/journal. pone.0041276 
Modeer, T., Blomberg, C. C., Wondimu, B., Julihn, A., \& Marcus, C. (2010). Association between obesity, flow rate of whole saliva, and dental caries in adolescents. Obesity, 18(12), 2367-2373. doi:10.1038/ oby. 2010.63

Morzel, M., Jeannin, A., Lucchi, G., Truntzer, C., Pecqueur, D., Nicklaus, S., ... Ducoroy, P. (2012). Human infant saliva peptidome is modified with age and diet transition. Journal of Proteomics, 75 (12), 3665-3673. doi:10.1016/j.jprot.2012.04.028

Nagler, R. M. \& Hershkovich, O. (2005). Relationships between age, drugs, oral sensorial complaints and salivary profile. Archives of Oral Biology, 50(1), 7-16. doi:10.1016/j. archoralbio.2004.07.012

Nicklaus, S., Demonteil, L., \& Tournier, C. (2015). 8 - modifying the texture of foods for infants and young children. In Modifying food texture (Vol. Sensory analysis, consumer requirements and preferences). Elsevier Ltd. doi:10.1016/B978-1-78242-3348.09993-4

Pagès-Hélary, S., Andriot, I., Guichard, E., \& Canon, F. (2014). Retention effect of human saliva on aroma release and respective contribution of salivary mucin and $\alpha$ amylase. Food Research International, 64, 424-431. doi:10.1016/j.foodres.2014.07.013

Phan, V. A., Yven, C., Lawrence, G., Chabanet, C., Reparet, J. M., \& Salles, C. (2008). In vivo sodium release related to salty perception during eating model cheeses of different textures. International Dairy Journal, 18(9), 956-963. doi:10.1016/j.idairyj.2008. 03.015

Piombino, P., Genovese, A., Esposito, S., Moio, L., Cutolo, P. P., Chambery, A., ... Ercolini, D. (2014). Saliva from obese individuals suppresses the release of aroma compounds from wine. Plos One, 9(1). doi:10.1371/ journal.pone.0085611

Pionnier, E., Chabanet, C., Mioche, L., Taylor, A. J., Le Quere, J. L., \& Salles, C. (2004). 2. in vivo nonvolatile release during eating of a model cheese: relationships with oral parameters. Journal of Agricultural and Food Chemistry, 52(3), 565-571. doi:10.1021/ jf030545n
Ployon, S., Morzel, M., \& Canon, F. (2017). The role of saliva in aroma release and perception. Food Chemistry, 226, 212-220. doi:10. 1016/j.foodchem.2017.01.055

Poette, J., Lubbers, S., Maison, B., Andrito, I., Pernin, K., Guichard, E., ... Feron, G. (2010). The salivary reactor: an innovating tool for the categorization of food products through their aroma and taste compounds release profiles. In T. Hofmann, W. Meyerhof, \& P. Schieberle (Eds.), Advances and challenges in flavor chemistry and biology. proceedings of the 9th wartburg symposium (pp. 386-389). ISBN-10: 3-938896-38-9 ISBN-13: 978-3-938896-38-9. Deutsche Forschungsanstalt fur Lebensmittelchemie. Retrieved from https : / / haluniv- bourgogne. archives- ouvertes . fr / hal00719384

Prinz, J. F. \& Lucas, P. W. (1995). Swallow thresholds in human mastication. Archives of Oral Biology, 40(5), 401-403. doi:10. 1016/0003-9969(94)00185-E

Prinz, J. F. \& Lucas, P. W. (2000). Saliva tannin interactions. Journal of Oral Rehabilitation, 27(11), 991-994. doi:10.1046/j . 1365-2842.2000.00578.x

Quintana, M., Palicki, O., Lucchi, G., Ducoroy, P., Chambon, C., Salles, C., \& Morzel, M. (2009). Inter-individual variability of protein patterns in saliva of healthy adults. Journal of Proteomics, 72(5), 822-830. doi:10.1016/j.jprot.2009.05.004

Rolls, E. T. \& Rolls, J. H. (1997). Olfactory sensory-specific satiety in humans. Physiology \& Behavior, 61(3), 461-473. doi:10. 1016/S0031-9384(96)00464-7

Ruijschop, R. M. A. J., Burgering, M. J. M., Jacobs, M. A., \& Boelrijk, A. E. M. (2009). Retro-nasal aroma release depends on both subject and product differences: a link to food intake regulation? Chemical Senses, 34(5), 395-403. doi:10 . 1093 / chemse/ bjp011

Salles, C., Chagnon, M.-C., Feron, G., Guichard, E., Laboure, H., Morzel, M., ... Yven, C. (2011). In-mouth mechanisms leading to flavor release and perception. Critical Reviews in Food Science and Nutrition, 51 (1), 67-90. doi:10.1080/10408390903044693 
Schipper, R. G., Silletti, E., \& Vingerhoeds, M. H. (2007). Saliva as research material: biochemical, physicochemical and practical aspects. Archives of Oral Biology, 52(12), 1114-1135. doi:http://dx.doi.org/10.1016/ j.archoralbio.2007.06.009

Tournier, C., Rodrigues, J., Canon, F., Salles, C., \& Feron, G. (2015). A method to evaluate chewing efficiency in infants through food bolus characterization: a preliminary study. Journal of Texture Studies, 46(2), 113-119. doi:10.1111/jtxs.12116

van der Bilt, A. \& Fontijn-Tekamp, F. A. (2004). Comparison of single and multiple sieve methods for the determination of masticatory performance. Archives of Oral Biology, 49(3), 193-198. doi:10.1016/j.archoralbio. 2003.08.007

van Ruth, S. M. \& Roozen, J. P. (2000). Influence of mastication and saliva on aroma release in a model mouth system. Food Chemistry, 71(3), 339-345. Meeting on Interaction of Food Matrix with Small Ligands Influencing Flavor and Texture, UNIV DEGLI STUDI UDINE, UDINE, ITALY, JUN 23SEP 24, 1999. doi:10.1016/S0308-8146(00) 00186-2

Vandenberghe-Descamps, M., Laboure, H., Prot, A., Septier, C., Tournier, C., Feron, G., \& Sulmont-Rosse, C. (2016). Salivary flow decreases in healthy elderly people independently of dental status and drug intake. Journal of Texture Studies, 47(4), 353-360. 1st Food for Elderly International Conference, Hangzhou, PEOPLES R CHINA, OCT 16-17, 2016. doi:10.1111/jtxs.12191

Vors, C., Drai, J., Gabert, L., Pineau, G., Laville, M., Vidal, H., ... Feron, G. (2015). Salivary composition in obese vs normalweight subjects: towards a role in postprandial lipid metabolism? International Journal of Obesity, 39(9), 1425-1428. doi:10. 1038/ijo.2015.71

Yven, C., Guessasma, S., Chaunier, L., Della Valle, G., \& Salles, C. (2010). The role of mechanical properties of brittle airy foods on the masticatory performance. Journal of Food Engineering, 101(1), 85-91. doi:10. 1016/j.jfoodeng.2010.06.012
Yven, C., Culioli, J., \& Mioche, L. (2005). Meat bolus properties in relation with meat texture and chewing context. Meat Science, 70(2), 365-371. doi:10.1016/j . meatsci . 2005.01.002

Yven, C., Patarin, J., Magnin, A., Laboure, H., Repoux, M., Guichard, E., \& Feron, G. (2012). Consequences of individual chewing strategies on bolus rheological properties at the swallowing threshold. Journal of Texture Studies, 43(4), 309-318. doi:10. 1111/j.1745-4603.2011.00340.x 